\title{
ARTIGOS
}

\section{A sociedade dos adoecimentos no trabalho}

\author{
The society of illness at work
}

\author{
Ricardo Antunes* \\ Professor titular de Sociologia do Trabalho no IFCH/Unicamp, Campinas/SP, Brasil
}

Luci Praun ${ }^{* *}$

Professora do Programa de Psicologia da Saúde, vinculada à linha de pesquisa Processos psicossociais, da Universidade Metodista de São Paulo, Brasil; doutora em Sociologia pelo IFCH/Unicamp, Campinas/SP, Brasil

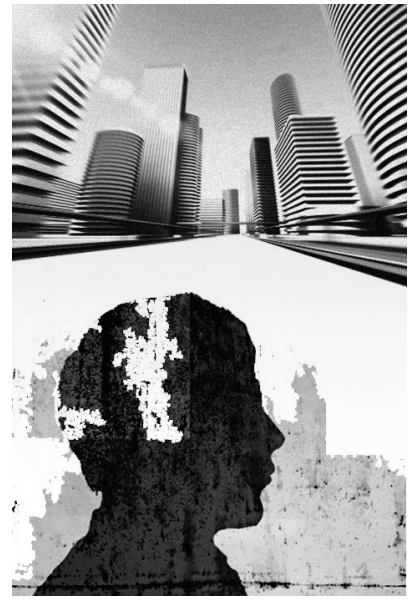

Resumo: Este artigo tem o objetivo de contribuir para as reflexões sobre os processos de saúde-adoecimento que impactam o mundo do trabalho no capitalismo contemporâneo. Parte de uma análise que articula as alterações ocorridas no interior dos locais de trabalho para um processo de maior amplitude, de reorganização do padrão de acumulação capitalista e do redesenho da divisão internacional do trabalho, fenômenos marcantes da sociabilidade capitalista na transição do século XX para o XXI.

Palavras-chave: Precarização. Saúde e trabalho. Reorganização do trabalho e da produção. Mundo do trabalho.

Abstract: This article aims at contributing to the thinking about the health-illness processes that make an impact on the labor world in the contemporary capitalism. It starts from an analysis linking the changes that occurred in the workplaces with a process of greater range, of reorganization of the pattern of capitalist accumulation, as well as of redesign of the international division of labor, which were outstanding phenomena of the capitalist sociability in the passage from the $\mathrm{XX}^{\text {th }}$ to the $\mathrm{XXI}^{\text {th }}$ century.

Keywords: Precariousness. Health and labor. Reorganization of labor and production. Labor world.

*E-mail: rlcantunes53@gmail.com.

**E-mail:1upraun@uol.com.br. 


\section{Introdução}

s transformações ocorridas no capitalismo desde as últimas três déca-
das do século XX impactaram profundamente o mundo do trabalho.
Após o longo período de crescimento da economia capitalista, inicia-
do no pós-guerra, os anos 1970 seriam marcados pela estagnação e pela crise, estampadas de forma mais visível na crise de acumulação taylorista e fordista, mas que encontravam suas determinações mais profundas, caracterizadas por uma crise estrutural do sistema do capital (Mészáros, 2002; Antunes, 2010).

Em resposta aos obstáculos impostos ao processo de acumulação, nos anos 1980, um conjunto de medidas, articuladoras de velhas e novas formas de exploração do trabalho, passou a redesenhar a divisão internacional do trabalho, alterando também de forma significativa a composição da classe trabalhadora em escala global. Movendo-se com facilidade pelo globo, fortemente enraizadas no capital financeiro, um número cada vez mais reduzido de corporações transnacionais passou a impor à classe-que-vive-do-trabalho, ${ }^{1}$ nos diferentes países do mundo, patamares salariais e condições de existência cada vez mais rebaixadas (Antunes, 2010, 2015).

Acompanhando o deslocamento de parcela considerável da atividade produtiva para áreas localizadas na periferia do sistema, o capitalismo contemporâneo presenciou, particularmente nos países de capitalismo avançado, a redução do proletariado industrial. Como parte do mesmo processo, em vários países no Sul do mundo, impulsionou a expansão significativa do contingente de trabalhadores e trabalhadoras ${ }^{2}$ abrigados nos setores de serviços, na agroindústria, assim como na indústria, especialmente. Em essência, a resposta do capital à sua crise baseou-

1. Noção ampliada de classe trabalhadora, que incorpora tanto os trabalhadores produtivos, presentes na indústria, na agricultura e também no setor de serviços, privatizados pela lógica dominante do capital financeiro, como aqueles assalariados improdutivos, que não geram mais-valia, mas que são imprescindíveis no processo de trabalho capitalista e vivenciam situações que têm clara similitude com aquelas experimentadas pelos(as) trabalhadores(as) produtivos. Como todo trabalho produtivo tende a ser assalariado, mas nem todo trabalhador assalariado é produtivo, uma noção ampliada de classe trabalhadora deve articular essas duas dimensões (Antunes, 2010).

2. Usaremos sempre a noção de trabalhadores contemplando sua dimensão de gênero, como trabalhadores e trabalhadoras, uma vez que há frequentemente uma divisão sociossexual desigual e diferenciada no mundo do trabalho. Assim, sempre que usamos a palavra trabalhadores, estamos concebendo também sua dimensão de gênero. 
-se, potencializada pela internacionalização da economia, em uma forma particular de articulação de estratégias de extração de mais-valia absoluta e relativa. Essas medidas seriam acentuadas a partir de 2008, em meio às novas manifestações da crise estrutural do sistema.

No Brasil, particularmente na década de 1990, as transformações geradas pela nova divisão internacional do trabalho foram de grande intensidade, já que partiram de uma dinâmica interna, característica dos países de industrialização dependente, fundada na superexploração da força de trabalho. A imposição de baixos salários, associados a ritmos de produção intensificados e jornadas de trabalho prolongadas, foi ainda acentuada pela desorganização do movimento operário e sindical, imposta pela vigência, entre 1964 e 1985, da ditadura militar (Antunes, 2010).

Portanto, esse é o contexto no qual, com a vitória do neoliberalismo no Brasil nos anos 1990, se desenvolve o processo de reestruturação produtiva. Um processo desencadeado em meio a condições de exploração particulares e articuladoras de elementos herdeiros do fordismo (ainda vigentes em vários ramos e setores produtivos) aos novos mecanismos, próprios das formas de acumulação flexível (Harvey, 2013).

A implantação de programas de qualidade total, dos sistemas just-in-time e kanban, além da introdução de ganhos salariais vinculados à lucratividade e à produtividade (de que é exemplo o programa de participação nos lucros e resultados — PLR), sob uma pragmática que se adequava fortemente aos desígnios neoliberais, possibilitou a expansão intensificada da reestruturação produtiva, tendo como consequências a flexibilização, a informalidade ${ }^{3}$ e a profunda precarização das condições de trabalho e vida da classe trabalhadora brasileira.

Parte dos efeitos desse processo materializa-se, conforme indicam diferentes pesquisas, na relação direta entre trabalho terceirizado e alta incidência de acidentes de trabalho, inclusive aqueles que resultam no óbito do trabalhador. Outra manifestação, bastante significativa, diz respeito aos adoecimentos com nexo laboral, sobretudo aqueles relacionados às lesões osteomusculares e transtornos mentais.

As mudanças em curso nas últimas décadas vêm produzindo indicadores de acidentes e doenças profissionais cada vez mais altos, mesmo que, por conveniên-

3. Se a informalidade (que ocorre quando o contrato de trabalho não obedece a legislação social protetora do trabalho) não é sinônimo direto de precariedade, sua vigência expressa formas de trabalho desprovido de direitos e, por isso, encontra clara similitude com a precarização. 
cia política e econômica, impere a não notificação, que se expressa de forma ainda mais aguda no caso das doenças profissionais. Este artigo tem por objetivo apresentar elementos que possam contribuir com a compreensão desse fenômeno.

\section{Trabalho e adoecimento no contexto da acumulação flexível}

\section{Os acidentes de trabalho ${ }^{4} \mathrm{e}$ as manifestações de adoecimento com nexo laboral ${ }^{5}$} não são fenômenos novos, mas processos tão antigos quanto a submissão do trabalho às diferentes formas de exploração. Sob o capitalismo, Engels (2010), baseado na observação direta e em outros estudos sobre as condições de trabalho no século XIX, descrevia, em 1845, como as condições de vida e trabalho do operariado de algumas cidades industriais inglesas encontravam-se na raiz de um conjunto de enfermidades que, não raramente, desdobravam-se na morte desses trabalhadores.

Ao longo do século XX, com a produção em massa e a ampliação do controle e intensificação do trabalho, proporcionado pela expansão do taylorismo-fordismo, novas formas de acidentes e adoecimentos com nexo laboral passaram a fazer parte do cotidiano do trabalho. ${ }^{6}$

4. Utilizaremos a expressão acidentes de trabalho em referência aos acidentes típicos, que são aqueles que ocorrem durante a jornada de trabalho, fatais ou não, geralmente causadores de lesões e ferimentos no corpo, fraturas, mutilações, entre outros impactos físicos.

5. A referência ao adoecimento ou enfermidade com nexo laboral será realizada considerando processos que resultem da exposição do trabalhador a condições de trabalho nocivas à sua saúde e que gerem como desdobramento o adoecimento físico e/ou mental.

6. No ABC paulista, espaço de concentração da indústria automobilística instalada no Brasil durante os anos 1950, as manifestações de adoecimento originadas pelo trabalho podem ser sintetizadas por uma reportagem publicada pelo jornal O Estado de S. Paulo, em 29 de janeiro de 1979. Nela ficam evidenciadas as condições particulares assumidas pelo trabalho no capitalismo periférico e sob o regime militar: "Se legalmente, para efeitos de aposentadoria, a velhice chega após os sessenta anos, no ABC, especialmente entre os operários do setor metalúrgico, a chamada terceira idade é antecipada: dos 840 sócios da Associação dos Aposentados Metalúrgicos de São Bernardo do Campo e Diadema, 530 interromperam suas atividades profissionais antes dos cinquenta anos, por invalidez. Os 310 restantes se aposentaram por tempo de serviço. 'Neurose, pressão alta acompanhada de derrame cerebral e moléstias da coluna vertebral são as doenças profissionais responsáveis pela maior parte das aposentadorias por invalidez.' O presidente do Sindicato dos Metalúrgicos de São Caetano do Sul, João Lins Pereira, exemplifica com o caso de um operário que, depois de várias tentativas, conseguiu sua aposentadoria por neurose pelo serviço. 'Adoecia ao se aproximar dos portões da fábrica. Consultou especialistas, fez tratamentos para os nervos, sem resultados. Afinal, foi descoberta a causa: trabalhou mais de cinco anos na empresa, sem folga e sem férias, fazendo de duas a quatro horas extras por dia"'. 
O que mudou então? Por um lado, a incorporação, ao cotidiano do mundo do trabalho, de novas enfermidades, típicas das recentes formas de organização do trabalho e da produção. Por outro, fruto da nova divisão internacional do trabalho, a disseminação de práticas que articulam os pressupostos da liofilização organizacional (Antunes, 2010), da empresa enxuta (lean production) a condições de baixa (ou nenhuma) proteção do trabalho.

A nova divisão internacional do trabalho estabeleceu, concomitantemente, um novo mapa de acidentes e doenças profissionais. Essas alterações acabam sendo perceptíveis com mais clareza no interior de corporações de grande porte, nas quais a gestão dos processos de trabalho é potencializada pela presença de robôs e sistemas informacionais e comunicacionais sofisticados. Mas vale acrescentar que essas condições, presentes no interior das grandes corporações, acabam por repercutir de diferentes maneiras ao longo da cadeia produtiva.

Dessa forma, por um lado, os trabalhadores pertencentes ao núcleo que atua com maquinário mais avançado, dotado de maior tecnologia, encontram-se cada vez mais expostos à flexibilização e à intensificação do ritmo de suas atividades, expressas não somente pela cadência imposta pela robotização do processo produtivo, mas, sobretudo, pela instituição de práticas pautadas pela multifuncionalidade, polivalência, times de trabalho interdependentes, além da submissão a uma série de mecanismos de gestão pautados na pressão psicológica voltada para o aumento da produtividade. Por outro, outra parcela da classe trabalhadora, numericamente superior, passa a experienciar, cada vez mais, diferentes modalidades de vínculos e condições de trabalho que se viabilizam a partir de ambientes de trabalho que articulam menor desenvolvimento tecnológico a jornadas mais extensas, maior insegurança e vulnerabilidade.

Essa divisão, muitas vezes perceptível a partir das condições da cadeia produtiva em cada país, é projetada em escala global, desenhando um mapa dos acidentes e doenças oriundas da atividade laborativa, cujo tipo e grau de incidência evidencia, de uma perspectiva ampla, parte das diferenças entre o centro e a periferia do sistema. Quanto mais frágil a legislação protetora do trabalho e a organização sindical na localidade, maior o grau de precarização das condições de trabalho, independentemente do grau de "modernização" das linhas de produção ou ambientes de trabalho como um todo (Praun, 2014).

Trata-se, nesse sentido, de um redesenho do mapa mundial dos acidentes e doenças profissionais e do trabalho cuja base de reconfiguração assenta-se em uma nova morfologia do trabalho expressa por clivagens e transversalidades entre 
trabalhadores estáveis e precários, homens e mulheres, jovens e idosos, brancos, negros e índios, qualificados e desqualificados, empregados e desempregados, nativos e imigrantes, entre tantos outros exemplos (Antunes, 2010).

Uma reconfiguração do trabalho que articula a ampliação de grandes contingentes que se precarizam ou perdem o emprego e vivenciam novos modos de extração de sobretrabalho e da mais-valia, conjuntamente com aqueles setores que atuam inseridos em ambientes de trabalho que fazem uso das chamadas tecnologias da informação e comunicação (TIC), dos trabalhadores e trabalhadoras em call center, telemarketing, supermercados, empresas de fast-food etc., o que denominamos como novo proletariado de serviços, que ganha papel de destaque nas lutas sociais e do trabalho no mundo contemporâneo (Ibidem).

\section{A flexibilização como base do adoecimento}

A flexibilidade ou flexibilização se constitui no contexto atual em uma espécie de síntese ordenadora dos múltiplos fatores que fundamentam as alterações na sociabilidade do capitalismo contemporâneo. Do ponto de vista de seu impacto nas relações de trabalho, a flexibilização se expressa na diminuição drástica das fronteiras entre atividade laboral e espaço da vida privada, no desmonte da legislação trabalhista, nas diferentes formas de contratação da força de trabalho e em sua expressão negada, o desemprego estrutural.

Pode ser percebida ainda, no dia a dia da atividade laboral, diante da forte sensação de que o tempo foi comprimido; ou também na clara densificação da jornada de trabalho, na qual todos se desdobram para executar sozinhos o que antes era feito por dois ou mais trabalhadores. Além disso, é visível por meio dos bancos de dias e horas que ajustam a jornada às demandas flexíveis do mercado, assim como através da instituição de uma parcela variável do salário subordinada ao cumprimento de metas de produção e "qualidade", entre outras formas de manifestação (Praun, 2014).

Essas diversificadas formas de manifestação da flexibilidade no cotidiano do trabalho, além de resultarem pura e simplesmente de adaptações organizacionais potencializadas por inovações tecnológicas, constituem um traço essencial da atual fase de desenvolvimento do capitalismo. O fenômeno da flexibilidade é parte da essência da onda de mundialização da economia desencadeada a partir da crise 
dos anos 1970, da qual a esfera financeira, tal como destacou Chesnais (1998), constitui elemento essencial.

Visto dessa perspectiva, a apreensão do significado do impacto da flexibilização no mundo do trabalho assume nova dimensão, uma vez que não se trata de característica contingencial, mas intrínseca às engrenagens da acumulação de capital. É nesse contexto que, conforme Alves (2000, p. 26), “o predomínio da financeirização sob o capitalismo mundial tende a incrementar a velocidade, a intensidade e amplitude do ser-precisamente-assim do capital, propiciando um salto qualitativo em seu potencial ofensivo sobre o trabalho assalariado".

Aflexibilização e sua expressão multifacetada no mundo do trabalho sintetiza o que parte dos autores da sociologia tem definido, desde os anos 1980, como precarização do trabalho. Compreendida como processo contraditório, a precarização desperta tanto resistências por parte dos trabalhadores como, tendencialmente, apresenta-se como processo contínuo, cujos mecanismos de imposição entrelaçam-se com as necessidades permanentes de valorização de capital e autorreprodução do sistema. Nesse sentido, a precarização é, por um lado, um fenômeno intrínseco à sociabilidade construída sob o signo do capital; por outro, uma forma particular assumida pelo processo de exploração do trabalho sob o capitalismo em sua etapa de crise estrutural, podendo, portanto, ser mais ou menos intensa, uma vez que não é uma forma estática. Nas épocas de crise - ainda mais quando esta tem um claro acento estrutural - o que se assiste é a sua intensificação, o que vimos denominando como a persistente tendência à precarização estrutural do trabalho em escala global, da qual o trabalho imigrante é sua expressão mais visível e brutal.

Não existem, nesse sentido, limites para a precarização, mas apenas formas diferenciadas de sua manifestação. Formas capazes de articular em uma única cadeia produtiva desde o trabalho terceirizado, quarteirizado, muitas vezes realizado nas casas dos próprios trabalhadores, àquele intensificado ao limite, desenvolvido nos ambientes "modernos" e "limpos" das corporações mundiais. Por isso que, sob a atual fase do capitalismo, o domínio do trabalho é, mais do que nunca, domínio do tempo de trabalho (Antunes, 2010 e 2015; Mészáros, 2007).

A título de exemplificação, pode-se citar o impacto das alterações realizadas no ciclo de operações de fixação dos freios ABS em picapes S10 produzidas na General Motors do Brasil. Executadas, antes da reorganização do processo, em 175 segundos (Actual Takt Time), as operações passaram a ser desenvolvidas, em 2008, com uma redução de tempo na ordem de quase 30\% (Praun, 2014, p. 113). 
Reduções como essas impactam, conforme declaração do vice-presidente de manufatura da GM América do Sul, de forma bastante significativa na produção da fábrica e, consequentemente, na cadeia produtiva como um todo. Conforme declarou o executivo: "Graças à tecnologia e ao processo de melhorias contínuas, podemos ganhar um segundo a mais, dois segundos a mais no ciclo de cada veículo. Para se ter uma ideia da importância disso, em Gravataí, que tem capacidade para 360 mil unidades por ano, ganhar um segundo, só nas operações de gargalo da produção, significa 7 mil carros a mais por ano"7 (Praun, 2014, p. 25).

A pressão pela capacidade imediata de resposta dos trabalhadores às demandas do mercado, cujas atividades passaram a ser ainda mais controladas e calculadas em frações de segundos, assim como a obsessão dos gestores do capital em eliminar completamente os tempos mortos dos processos de trabalho, tem convertido, paulatinamente, o ambiente de trabalho em espaço de adoecimento.

Esse contexto foi considerado por Sato (2003), que identificou, entre os fatores que contribuem para a maior incidência do processo de adoecimento, a progressiva diminuição ou ausência do mínimo de controle dos trabalhadores sobre o processo de trabalho. Para a autora, essa ausência constitui-se em risco real para o desenvolvimento de diferentes formas de adoecimento que se desdobram em "problemas osteoarticulares, distúrbios gastrintestinais, alterações cardiovasculares, distúrbios de saúde mental e acidentes de trabalho" (p. 41).

\section{Laços solidários rompidos: individualização e solidão no local de trabalho}

A origem desses processos de adoecimento tem também como pano de fundo, entre outros, o crescente processo de individualização do trabalho e a ruptura do tecido de solidariedade antes presente entre os trabalhadores. ${ }^{8}$ É essa quebra dos laços de solidariedade e, por conseguinte, da capacidade do acionamento das estratégias coletivas de defesa entre os trabalhadores que se encontra na base do aumento dos processos de adoecimento psíquico e de sua expressão mais contundente: o suicídio no local de trabalho (Dejours e Bègue, 2010).

7. Declaração do vice-presidente de manufatura da GM América do Sul à revista Panorama, de fevereiro de 2013, editada pela General Motors do Brasil citada por Praun (2014, p. 25).

8. Ver, dentre outros, os estudos desenvolvidos por Linhart (2007); Dejours (2008), Dejours e Bègue (2010), Gaulejac (2007), Seligmann-Silva (2007 e 2011). 
A presença dos laços de solidariedade, hoje rompidos, estaria na raiz da baixa incidência de suicídios nos locais de trabalho no período que antecede aos anos 1980, pontuam Dejours e Bègue (2010). Naquele período, a capacidade gestada na coletividade de converter situações de sofrimento em um jogo de chacotas e escárnio acabava por criar condições capazes de mascarar situações desfavoráveis e tecer entre os integrantes do grupo pactos de apoio subjetivo mútuo. Em situações mais extremadas, quando o trabalhador não conseguia dissimular seu sofrimento, os próprios laços de solidariedade constituídos acabavam, não raras vezes, sendo acionados de forma a protegê-lo ou confortá-lo. O desmonte dessas condições tem contribuído, conforme os autores, para o aumento da incidência de suicídios nos locais de trabalho. Esses, por sua vez, são o resultado extremado de um processo de sofrimento psíquico, mas já destituído do apoio e solidariedade dos demais.

Para os autores acima citados, que pesquisaram a incidência desses episódios na França durante os anos 2000, um suicídio, como toda conduta humana, é uma mensagem endereçada à comunidade da qual seu sujeito faz ou fazia parte. Trata-se, conforme os autores, de uma "mensagem brutal", que versa sobre a solidão que emerge das novas formas de organização e gestão do trabalho.

Que um suicídio possa ocorrer no local de trabalho indica que todas essas condutas de ajuda mútua e solidariedade — que não era nem mais nem menos que uma simples prevenção das descompensações, assumida pelo coletivo de trabalho - foram banidas dos costumes e da rotina da vida de trabalho. Em seu lugar instalou-se a nova fórmula do cada um por si, e a solidão de todos tornou-se regra. Agora, um colega afoga-se e não se lhe estende mais a mão. Em outros termos, um único suicídio no local de trabalho - ou manifestamente em relação ao trabalho — revela a desestruturação profunda da ajuda mútua e da solidariedade. (Dejours e Bègue, 2010, p. 21)

O suicídio é a expressão radicalizada da deterioração das condições de trabalho sob a vigência da gestão flexível. Ele e todo o sofrimento que o cerca encontram espaço para se desenvolver na medida em que o trabalhador se vê diante de uma organização do trabalho voltada para o controle acentuado de sua atividade, sob condições de trabalho em que as margens para a autonomia e o improviso, mesmo que bastante já limitadas na fase anterior do capitalismo, tenham sido gradativamente eliminadas. Uma organização do trabalho que oscila o tempo todo entre o discurso de valorização e o controle físico e mental extremados (Praun, 2014).

Esses ambientes, marcados pela lógica da gestão flexível, tendem a fragilizar "o conjunto de instâncias e forças" outrora existentes, "que presidem à mobilização 
dos indivíduos na defesa de sua saúde física e mental — defesa que se dá em um mundo compartilhado", já distante do vivenciado em dias atuais (Davezies, apud Seligmann-Silva, 2011, p. 467).

Convém destacar que parte dessas instâncias que favoreciam a existência desse sentimento de coletividade, de pertencimento, manifestava-se na capacidade de mobilização coletiva e na presença de entidades sindicais politicamente fortalecidas, o que sem dúvida também contribuía no sentido do amparo aos trabalhadores frente ao sofrimento vivenciado dentro e fora do local de trabalho. A ofensiva do capital sobre o trabalho, ao submetê-lo à lógica destrutiva do capital, promovendo a individualização e o isolamento é, nesse sentido, uma ação que busca cotidianamente desmontar sua manifestação de classe historicamente antagônica aos interesses da ordem capitalista.

\section{A gestão por metas}

Entre os diferentes mecanismos que buscam o envolvimento e o engajamento dos trabalhadores nos objetivos das corporações, assumem destaque na transição da década de 1980 para a seguinte aqueles organizados a partir de sistemas de metas.

A gestão por metas começou a ser disseminada nos ambientes de trabalho como desdobramento das primeiras medidas de reestruturação produtiva, implantadas a partir dos anos 1980. Esse modelo de gestão coincidiu com o fortalecimento de uma lógica de racionalização da economia global, com repercussão no mundo do trabalho, fundada na crescente mensuração de resultados. Sua mola propulsora foi fundada em duas características marcantes do período aberto pela crise dos anos 1970: a crescente financeirização das grandes corporações, como parte de um processo mais amplo de mundialização financeira, tal como aponta Chesnais (1996), e a necessidade intrínseca de aceleração, fruto da intensificação da concorrência intercapitalista e da pressão crescente dos investidores, dos ciclos de renovação e aumento dos indicadores de produtividade.

A obtenção desses indicadores, segundo Dejours (2010), entrelaça-se ao princípio toyotista de melhorias contínuas e seu almejado desdobramento, a qualidade total, largamente adotado pelas corporações mundiais. Encontra-se ainda em perfeita sintonia com o fenômeno que Linhart (2000 e 2007) denominou como individualização do trabalho. Se por um lado o princípio da qualidade total, quando subtraído do discurso ideológico que o sustenta, caminha essencialmente na direção 
da eliminação dos poros da jornada e do trabalho vivo do processo produtivo, a crescente individualização do trabalho funcionaria, de acordo com a autora, como uma espécie de arremate das alterações vivenciadas dentro e fora dos locais de trabalho. A individualização, desse modo

evoca um novo período, que se abre em uma fantástica ambivalência em que com os terríveis desafios impostos pela concorrência, o cliente sairia triunfante, mas o assalariado também, pois a empresa, para satisfazer esse cliente nas melhores condições, é forçada à excelência, imperativo que repercute em todos os níveis da hierarquia. $\mathrm{O}$ que implicaria uma nova organização do trabalho, oferecendo as condições para cada qual desenvolver suas competências a serviço da variedade, da qualidade e da rapidez. (Linhart, 2007, p. 227)

Impregnadas da lógica concorrencial típica do padrão flexível de acumulação e de sua expressão político-ideológica neoliberal, as relações sociais como um todo e sua expressão nos locais de trabalho materializam-se cada vez mais em um projeto que se apresenta de forma paradoxal. Um projeto que transita entre as incertezas do mercado e a necessidade do engajamento como saída para se manter empregado; entre o reconhecimento de uma realidade aparentemente exterior ao indivíduo, perpassada pelas mais diversas formas de precarização do trabalho, e o discurso de valorização de suas potencialidades cotidianamente propagado no ambiente de trabalho.

É nesse marco que se inserem as estratégias corporativas de gestão por metas: a participação nos lucros e resultados (PLR) ou, simplesmente, participação nos resultados (PR). Essas estratégias, além de seu efeito prático de flexibilização salarial, funcionam como uma espécie de compensação (ou recompensa) pelo esforço e engajamento de cada trabalhador no alcance das metas estipuladas pela corporação.

A referência à participação nos lucros e/ou nos resultados obtidos pela corporação se constitui, nesse contexto, em clara alusão a uma suposta repartição dos ganhos de produtividade alcançados. Sua adoção, no entanto, sintetiza pelo menos três estratégias de controle que podem ser largamente observadas, conforme sistematiza Sato (2003), nos ambientes de trabalho dos anos 1990 em diante: o direcionamento da tarefa a ser executada pelo trabalhador, a avaliação do seu desempenho e a premiação por disciplinamento.

É importante destacar que as metas da PLR/PR são estabelecidas a cada ano, o que equivale a dizer que a vida do local de trabalho se organiza, na maior parte dos meses, em torno do seu cumprimento. A PLR/PR é, nesse sentido, um meca- 
nismo a mais para alavancar o ritmo de produção, a disciplinarização do trabalho, bem como o ambiente difuso de vigilância entre os trabalhadores. Essa disciplina e vigilância muitas vezes prescinde da presença direta do chefe.

Dessa forma, o gerenciamento por metas opera em diferentes sentidos: a) no desenvolvimento de mais um mecanismo disciplinador do trabalho, como na instituição de uma espécie de engajamento "voluntário" dos trabalhadores visando o aumento da produtividade; b) no incentivo ao controle de faltas exercido, não raro, entre os próprios trabalhadores dos times de produção/equipes de trabalho; c) na instituição da diminuição do tempo de repouso; d) na promoção da competição entre os trabalhadores e suas equipes visando o recebimento dos valores estipulados nos acordos firmados para essa finalidade; e) no aprofundamento das experiências de acordos coletivos firmados por empresas (Praun, 2014).

No Brasil, os acordos que articulam remuneração flexível e metas ganham relevância na segunda metade dos anos 1990, logo após a regulamentação, em 1994, ${ }^{9}$ do sistema de PLR. Instituídos, conforme consta no primeiro artigo da Lei n. 10.101/2000, "como instrumento[s] de integração entre capital e trabalho e como incentivo à produtividade", os acordos coletivos que estabelecem a PLR ou a PR articulam uma série de precondições, expressas em metas, que determinam os indicadores a serem atingidos para que o trabalhador receba a remuneração acordada.

Enquanto instrumentos privilegiados da gestão por metas, esses acordos envolvem recorrentemente o alcance de pelo menos quatro indicadores ${ }^{10}$ — produção, assiduidade-absenteísmo, parâmetros de qualidade, redução de custos — que pretendem impulsionar um desempenho pautado pela ampliação da produtividade e competitividade da empresa no mercado.

9. A PLR é instituída pela Medida Provisória n. 794, de 1994. Seis anos depois o sistema passa a ser regulamentado pela Lei n. 10.101, de 19/12/2000.

10. Um estudo realizado pelo Dieese (2006) a partir de 123 acordos de PLR firmados em 2005, mais de dez anos depois da medida provisória sobre o tema, o setor industrial (73\%), particularmente a categoria metalúrgica (36,6\%), ainda concentrava a maioria desses acordos. O mesmo estudo aponta que $78 \%$ dos acordos então analisados continham cláusulas que vinculavam o recebimento do valor acordado ao cumprimento de metas relacionadas à produtividade e à competitividade da empresa no mercado. Essas metas muitas vezes se expressaram por meio de indicadores sobre assiduidade/absenteísmo (42,3\%), volume de produção $(17,1 \%)$, lucro $(36,6 \%)$, redução de despesas $(21,1 \%)$, redução de refugos $(12,2 \%)$, produtividade $(8,9 \%)$ e, inclusive, contraditoriamente, conforme veremos mais adiante, redução de acidentes $(23,6 \%)$. Outro indicador que também aparece na pesquisa realizada pelo Dieese como constante nos acordos, presente em $35,8 \%$ dos documentos analisados, é o de conformidade, que, ao ligar-se à qualidade do resultado do trabalho, pode também ser inserido no contexto geral dos indicadores de produtividade. 
Vale lembrar que a instituição do sistema de PLR coincidiu, no Brasil, com a medida de desindexação salarial imposta pelo governo federal como parte do Plano Real. Ocorreu concomitante ao fim do ciclo dos Acordos das Câmaras Setoriais, que deram impulso ao processo de reestruturação produtiva. Passaram a vigorar também em meio à fase denominada por Alves (2000) como de expansão do "toyotismo sistêmico". Não por acaso, o polo disseminador dos acordos de PLR foi o da indústria automobilística instalada na região do $\mathrm{ABC}$ paulista, laboratório de um conjunto de medidas de flexibilização do trabalho e da produção.

Sobre esses acordos, é curioso perceber que, apesar de firmados no contexto de uma prática de negociação que institui as chamadas contrapartidas, os que tratam especificamente de PLR ou PR passam longe delas. Se nos acordos por fábrica as empresas passaram a impor a ideia da contrapartida como forma de barganhar a retirada de direitos anteriormente adquiridos "em troca" de novos investimentos na planta produtiva, no caso daqueles de remuneração flexível, a perspectiva se coloca ainda mais favorável à empresa. O cumprimento das metas estabelecidas, que implicam o aumento da intensidade do trabalho e da produtividade, não vem acompanhado de nenhum compromisso por parte das corporações sobre a melhora das condições de trabalho, como limites da jornada de trabalho, ritmo de produção ou outros instrumentos que preservem a saúde do trabalhador.

Os estudos de Pina e Stotz (2011) sobre os acordos firmados pelo Sindicato dos Metalúrgicos do ABC com as montadoras da região entre 2001 e 2008, apontam que em alguns casos, como no dos acordos firmados no período com a Ford, são considerados indicadores relativos à segurança do trabalho. Contudo, a presença desse indicador, expresso por meio da apuração de um Índice de Comportamento Seguro, não deixa dúvida sobre a concepção de segurança em questão. Os problemas de segurança na fábrica, longe de estarem relacionados às condições gerais e específicas de desenvolvimento do trabalho, encontram-se vinculados à postura do trabalhador, individualizada, frente ao processo produtivo. Nesse contexto, o acidente, quando ocorre, é fruto de um comportamento inseguro.

\section{0 assédio como estratégia de gestão}

Espaços de trabalho propulsores de altos índices de desempenho e produtividade, estruturados com base nas exigências que cada vez mais extrapolam a capacidade física e mental humana em suportá-las, não conseguem manter-se senão por 
meio de diferentes e sofisticados mecanismos de controle e coerção. $\mathrm{O}$ assédio moral é parte dessa engrenagem.

Práticas associadas ao assédio moral são, como sabido, anteriores aos processos de reorganização do trabalho e da produção vivenciados desde as últimas décadas do século XX. Apesar disso, será no contexto da acumulação flexível que esse tipo de prática assume novo significado e dissemina-se com vigor pelo mundo do trabalho.

“Todos estão expostos", assinala Barreto (2013, p. 18). Apesar de na maioria das vezes ser direcionado a um trabalhador específico, o assédio repercute sobre o coletivo. Em se tratando de uma ferramenta de gestão, sua prática, apesar de personificada na figura de um chefe, supervisor ou outro agente cuja relação de poder possa desencadeá-la, encontra-se em consonância com o conjunto de diretrizes que ordenam o trabalho coletivo na empresa (Barreto, 2013; Barreto, Heloani, 2013; Gaulejac, 2007).

As práticas dessa natureza são ferramentas de gestão voltadas para garantir, por meio da pressão institucionalizada, tanto o aumento constante da produtividade como o isolamento e a exclusão daqueles que se constituem como "barreiras" para sua plena realização.

\section{Terceirização: porta aberta para os acidentes e mortes no trabalho}

Na última década a terceirização vem se convertendo em instrumento central das estratégias de gestão corporativa. A importância desse mecanismo de contratação, entre outros aspectos, deve-se ao fato de, ao dissimular as relações sociais estabelecidas entre capital e trabalho, convertendo-as em relações interempresas, viabiliza maior flexibilidade das relações de trabalho, impondo aos trabalhadores contratos por tempo determinado, de acordo com os ritmos produtivos das empresas contratantes, auxiliando também, de forma importante, na desestruturação da classe trabalhadora (Antunes e Druck, 2014; Druck, 2011).

A explosão de empresas terceirizadas tem sido ainda um importante propulsor de empresas geradoras de mais-valia que, no passado recente, eram estatais prestadoras de serviços sem fins lucrativos. Com a privatização, elas se tornaram partícipes diretas ou indiretas no processo de valorização do capital, incrementando e ampliando as modalidades de extração direta ou indireta de mais-valia. 
No caso brasileiro constata-se, então, uma verdadeira epidemia nas últimas duas décadas, que contaminou a indústria, os serviços, a agricultura, o serviço público, generalizando-se também não só para as atividades-meio, mas também para as atividades-fim. Desse modo, evidencia-se, através das mais distintas modalidades da terceirização, novas condições de trabalho que definem trabalhadores de "primeira" e "segunda" categorias, que revela a distinção ou a condição de inferioridade e desigualdade.

As diferenças acentuam-se também nas jornadas mais prolongadas, nos ritmos e intensidade do trabalho, nos níveis mais altos de rotatividade (turn over), nos salários reduzidos, nas condições de insegurança, insalubridade, entre tantas outras. Assim, a terceirização aumenta ainda mais a fragmentação, a heterogeneização e a divisão intraclasse trabalhadora, ampliando a concorrência entre os que trabalham no mesmo espaço produtivo. ${ }^{11}$ Impõe, dessa forma, uma pulverização dos sindicatos, fazendo com que não raro, em uma mesma empresa, os trabalhadores dos diferentes setores terceirizados (como limpeza, vigilância, alimentação, manutenção etc.) tenham representação sindical diferenciada, fragmentando ainda mais suas possibilidades de organização, união, solidariedade e resistência de classe.

Nos diversos setores pesquisados em Riqueza e miséria do trabalho no Brasil, v. I, II e III (Antunes, 2006, 2013, 2014), pode-se constatar como entre os bancários, call center e telemarketing, petroquímicos e petroleiros, energia elétrica, comunicações, saúde, dentre vários outros setores, revelam-se múltiplas formas de diferenciação entre os trabalhadores terceirizados, tanto nos tipos diferenciados de contrato, na remuneração, nas condições de trabalho, como na representação sindical (ver também Druck, 1999).

Em estudo relativamente recente, realizado pelo Dieese, os setores considerados "tipicamente terceirizados" correspondiam a $25,5 \%$ dos empregos formais no Brasil, sendo sua remuneração $27,1 \%$ menor do que a praticada entre os demais

11. Em 2000, em pesquisa nas empresas petroquímicas e químicas na Bahia, onde foram entrevistados 358 trabalhadores diretamente contratados por 52 empresas do setor, revela-se como a terceirização é vista pelos trabalhadores desse segmento industrial. Perguntados se gostariam de ser terceirizados, 93\% responderam que não. Dentre esses, as principais justificativas para não serem terceirizados foram: para 47\%, significa a perda de direitos, de benefícios, de recompensa e de salários. Para 11\%, instabilidade e insegurança; para 7\% faltam condições de trabalho. Os demais entrevistados indicaram motivos diversos, que podem ser sintetizados em: discriminação, desvalorização e humilhação. Centro de Recursos Humanos/UFBa e Sindicato dos Químicos e Petroleiros (2000, Relatório da Pesquisa Campanha Salarial, apud Antunes e Druck, 2014, p.18). 
empregados formalizados. No que concerne à jornada de trabalho, os terceirizados trabalham em media três horas a mais, com um tempo de permanência no emprego $55,5 \%$ menor do que o dos demais empregados. A taxa de rotatividade/turn over entre os trabalhadores terceirizados é de $44,9 \%$, enquanto nas demais empresas é de 22,0\% (Dieese-CUT, 2011, apud Antunes e Druck, 2014).

Essas precárias condições de trabalho têm contribuído de forma significativa para a deterioração das condições de saúde e segurança no trabalho no Brasil. Vários estudos de casos revelam o quanto os terceirizados são os mais vulneráveis e onde os riscos e de acidentes têm sido maiores. É o caso de setores estratégicos, como os de energia elétrica, extração e refino de petróleo e siderurgia. ${ }^{12} \mathrm{O}$ exemplo dos trabalhadores na indústria de petróleo é expressivo, uma vez que o processo de terceirização tem se intensificado enormemente nas últimas duas décadas: a relação entre trabalhadores terceirizados e aqueles contratados diretamente pela Petrobras, em 2012, era de quatro terceirizados para cada funcionário efetivo. Segundo o Relatório de Sustentabilidade da Petrobras, referente a 2012, a empresa estatal tinha, então, 85.065 empregados contratados e 360.372 terceirizados (Petrobras, apud Antunes e Druck, 2014).

Dados apresentados pela Federação Única dos Petroleiros (FUP), filiada à CUT, mostram que de 1995 até 2010 foram registradas 283 mortes por acidentes de trabalho, das quais 228 ocorreram com trabalhadores terceirizados. ${ }^{13} \mathrm{O}$ crescimento dos trabalhadores terceirizados na empresa de energia elétrica Eletrobras também é alarmante: em 2011 havia 8.248 terceirizados e no ano seguinte esse contingente de trabalhadores subiu para 12.815 , significando um aumento de $55 \%$, ao mesmo tempo em que o número de empregados cresceu apenas $13 \%{ }^{14}$

12. Estudo realizado em 2010, com base em dados da Fundação Coge, revelou que "entre 2006 e 2008 morreram 239 trabalhadores por acidente de trabalho, dentre os quais 193, ou 80,7\%, eram trabalhadores terceirizados". No mesmo período, a taxa de mortalidade média entre os trabalhadores formalizados foi de 15,06, "enquanto que entre trabalhadores terceirizados foi de 55,53" (Dieese, 2011).

13. Conforme depoimentos de dirigentes sindicais: "É bem conhecida pelo conjunto dos trabalhadores a desigualdade das condições de segurança nas empresas da categoria [...]. Frequentemente os terceirizados, embora em uma mesma planta industrial, por vezes desenvolvendo as atividades com maior exposição ao risco, estão completamente desprotegidos coletiva e individualmente. Quando da ocorrência de acidentes, tem sido habitual a omissão das empresas principais contratantes, alegando que não têm nada a ver com o trabalhador e que o contrato é de serviço, e não de pessoal. [...] o número de vítimas é crescente entre os trabalhadores terceirizados (Sindiquímica, 2001, p. 7, apud Druck e Franco, 2007).

14. Segundo Relatório Anual e de Sustentabilidade, Eletrobras, 2012, p.184, apud Antunes e Druck, 2014 , p. 20. 
Em contraposição ao discurso empresarial que justifica a terceirização como parte da "modernização" das empresas na era da globalização, visando maior "especialização" das atividades produtivas, as pesquisas atestam que as empresas terceirizam também para a transferir os riscos para os trabalhadores, desobrigando-se de cumprir e seguir as exigências da legislação e dos direitos trabalhistas, que se tornam de responsabilidade das empresas de terceirização. Assim, a terceirização tornou-se um dos elementos centrais do atual processo de precarização do trabalho no Brasil, constituindo-se num fenômeno presente praticamente em todos os ramos, setores e espaços do trabalho, pois é uma prática de gestão/organização/controle da força de trabalho que discrimina, ao mesmo tempo em que flexibiliza os contratos, eximindo-se da proteção trabalhista.

\section{Resgatar 0 sentido de pertencimento de classe}

Em sua lógica destrutiva, o capital não reconhece nenhuma barreira para a precarização do trabalho. A exploração sem limites da força de trabalho é em si expressão das contradições estruturais de dada forma de sociabilidade que, ao mesmo tempo em que não pode prescindir do trabalho vivo para sua reprodução, necessita explorá-lo ao extremo, impondo-lhe o sentido mais profundo de sua mercantilização: a abreviação de seu tempo de uso como resultado do aprofundamento, pelo adoecimento, de sua característica de mercadoria de alta descartabilidade.

As mudanças ocorridas no mundo do trabalho nas últimas décadas resultaram na constituição de um exército de trabalhadores mutilados, lesionados, adoecidos física e mentalmente, muitos deles incapacitados de forma definitiva para o trabalho.

Em outras palavras, trata-se de um modelo de gestão que ao mesmo tempo em que se organiza visando o envolvimento da subjetividade inautêntica (Antunes, 2010), o controle da subjetividade (Linhart, 2007) dos trabalhadores, mecanismo necessário para a obtenção de altos índices de produtividade, configura-se cada vez mais como incapaz, pela própria intensidade concorrencial e instabilidade do mercado, de garantir condições de trabalho minimamente adequadas à saúde física e mental dos trabalhadores.

Não se trata, portanto, de mero acaso que a maior incidência de casos de lesões por esforços repetitivos/distúrbios osteomusculares relacionados ao trabalho (LER/ Dort) e de transtornos mentais ocorra simultaneamente à disseminação em escala 
global dos processos de reorganização do trabalho e da produção e, de maneira articulada, à expansão das diferentes formas de precarização do trabalho, entre elas a expansão da terceirização.

É diante desse cenário que novos desafios se impõem aos sindicatos. De nossa parte, cremos que a ferramenta-sindicato ainda é imprescindível, enquanto perdurar a sociedade do capital, com sua exploração do trabalho, suas precarizações, seus adoecimentos e seus padecimentos corpóreos físicos, psíquicos etc. Mas é preciso dizer que há inúmeros desafios a ser enfrentados.

Por um lado impõe-se a necessidade de adoção de estratégias de organização e luta que considerem a nova morfologia assumida pelo trabalho no capitalismo contemporâneo. É urgente que as entidades representativas dos trabalhadores rompam com a enorme barreira social que separa os trabalhadores "estáveis", em processo franco de redução, daqueles submetidos às jornadas de tempo parcial, precarizados, subproletarizados, em significativa expansão no atual cenário mundial. Impõe-se o desafio de articular uma efetiva dimensão de classe, no sentido amplo de classe trabalhadora, em sua nova morfologia, articulando-a com outras dimensões decisivas, como a de gênero, a geracional e a étnica (Antunes, 2010 e 2015).

Essa é condição essencial para fazer frente, do ponto de vista imediato, às constantes tentativas de desmonte dos direitos e flexibilização do trabalho. O eufemismo "flexibilizar", expresso nos discursos que propõem o fim da Consolidação das Leis Trabalhistas (CLT), é a forma branda encontrada pelas forças do capital para desconstruir os direitos do trabalho, arduamente conquistados em tantas décadas de embates e batalhas. Basta olhar o que se passa hoje com a Europa e constatar que lá também o receituário é flexibilizar, acentuando ainda mais o desmonte dos direitos trabalhistas.

As flexibilizações, terceirizações, o aumento da informalidade e a ampliação do desemprego serão ainda mais intensas se a CLT for desfigurada ou eliminada. $\mathrm{E}$ a atual tentativa de liberar plenamente a terceirização, conforme propõe o PL n. 4.330, é um passo brutal rumo ao fim dos direitos do trabalho consagrados na CLT e à nefasta sociedade da terceirização total.

Do ponto de vista estratégico, se forem capazes de unir os laços de solidariedade e o sentido de pertencimento de classe, conjugando suas ações, as entidades representativas dos trabalhadores poderão, mais do que qualquer outra força social, ser efetivamente capazes de demolir o sistema de metabolismo societal do capital e sua lógica destrutiva e, desse modo, capazes de começar a desenhar um novo 
modo de vida. E os sindicatos de classe ainda poderão ter um papel de destaque nesse processo, se forem capazes de entender o século XXI e, em especial, compreender a nova morfologia do trabalho.

Recebido em 28/5/2015 - Aprovado em 8/6/2015

\section{Referências bibliográficas}

ALVES, Giovanni. O novo (e precário) mundo do trabalho: reestruturação produtiva e crise do sindicalismo. São Paulo: Boitempo, 2000.

ANTUNES, Ricardo. Adeus ao trabalho? Ensaio sobre as metamorfoses e a centralidade do mundo do trabalho. São Paulo: Cortez, 2015. (Edição especial de 20 anos.)

. Os sentidos do trabalho: ensaio sobre a afirmação e a negação do trabalho. São Paulo: Boitempo, 2010.

ANTUNES, Ricardo (Org.). Riqueza e miséria do trabalho. São Paulo: Boitempo, 2006. v. I. (Org.). Riqueza e miséria do trabalho. São Paulo: Boitempo, 2013. v. II.

(Org.). Riqueza e miséria do trabalho. São Paulo: Boitempo, 2014. v. III.

; DRUCK, Graça. A epidemia da terceirização. In: ANTUNES, Ricardo (Org.). Riqueza e miséria do trabalho. São Paulo: Boitempo, 2014. v. III, p. 13-24.

BARRETO, Margarida. Assédio moral: trabalho, doenças e morte. In: SEMINÁRIO COMPREENDENDO O ASSÉDIO MORAL NO AMBIENTE DE TRABALHO [manuscrito]: [Anais]/coordenação técnica, Cristiane Queiroz, Juliana Andrade Oliveira, Maria Maeno. São Paulo: Fundacentro, 2013.

BARRETO, Margarida; HELOANI, Roberto. Assédio laboral e as questões contemporâneas à saúde do trabalhador. In: LOURENÇO, Edvânia Ângela de Souza; NAVARRO, Vera Lúcia. $O$ avesso do trabalho III. Saúde do trabalhador e questões contemporâneas. São Paulo: Outras Expressões, 2013. p. 107-123.

CHESNAIS, François. A mundialização do capital. São Paulo: Xamã, 1996.

(Coord.). A mundialização financeira: gênese, custos e riscos. São Paulo: Xamã, 1998. 
DEJOURS, Christophe. A avaliação do trabalho submetida à prova do real. In: SZNELWAR, Laerte Idal; MASCIA, Fausto Leopoldo (Orgs.). Cadernos TTO. São Paulo: Blucher, 2008. ; BÈGUE, Florence. Suicídio e trabalho: o que fazer? Brasília: Paralelo 15, 2010.

DIEESE. Participação dos Trabalhadores nos Lucros e Resultados das Empresas — 2005. Estudos e Pesquisas, ano 3, n. 22, ago. 2006.

. Terceirização e desenvolvimento: uma conta que não fecha. Dossiê sobre o impacto da terceirização sobre os trabalhadores e propostas para garantir a igualdade de direitos. S/1, set. 2011. Disponível em: <http://2013.cut.org.br/sistema/ck/files/terceirizacao.PDF>. Acesso em: 16/06/2015.

DRUCK, Graça. Terceirização: desfordizando a fábrica — um estudo do complexo petroquímico da Bahia. São Paulo: Boitempo/Edufba, 1999.

. Trabalho, precarização e resistências. Caderno CRH, Salvador, UFBA, v. 24, 2011.

; FRANCO, Tânia. A perda da razão social do trabalho: terceirização e precarização. São Paulo: Boitempo, 2007.

ENGELS, Friedrich. A situação da classe trabalhadora inglesa. São Paulo: Boitempo, 2010.

GAULEJAC, Vincent de. Gestão como doença social: ideologia, poder gerencialista e fragmentação social. Aparecida: Ideias e Letras, 2007.

HARVEY, David. A condição pós-moderna. São Paulo: Loyola, 2013.

LINHART, Danièle. O indivíduo no centro da modernização das empresas: um reconhecimento esperado, mas perigoso. Trabalho \& Educação, Belo Horizonte, n. 7, p. 24-36, jul./ dez. 2000.

. A desmedida do capital. São Paulo: Boitempo, 2007.

MÉSZÁROS, István. Para além do capital. São Paulo: Boitempo, 2002.

. O desafio e o fardo do tempo histórico: o socialismo do século XXI. São Paulo: Boitempo, 2007.

O ESTADO DE S. PAULO. ABC, onde a idade não define a velhice. São Paulo, 29 jan. 1979.

PETROBRAS. Relatório de sustentabilidade 2012. Disponível em: <http://www.investidorpetrobras.com.br/pt/governanca/relatorio-de-sustentabilidade/relatorio-de-sustentabilidade-2012.htm>. Acesso em: 16 jun. 2015.

PINA, José Augusto; STOTZ, Eduardo Navarro. Participação nos lucros ou resultados e banco de horas: intensidade do trabalho e desgaste operário. Revista Brasileira de Saúde Ocupacional, São Paulo, v. 36, n. 123, p. 162-176, 2011. 
PRAUN, Lucieneida Dováo. Não sois máquina! Reestruturação produtiva e adoecimento na General Motors do Brasil. Tese (Doutorado em Sociologia) - Instituto de Filosofia e Ciências Humanas/Departamento de Sociologia, Universidade Estadual de Campinas, Campinas, 2014.

SATO, Leny. Saúde e controle no trabalho: feições de um antigo problema. In: JACQUES, Maria da Graça; CODO, Wanderley (Orgs.). Saúde mental e trabalho: leituras. Petrópolis: Vozes, 2003. p. 31-49.

SELIGMANN-SILVA, Edith. Psicopatologia no trabalho: aspectos contemporâneos. In: CONGRESSO INTERNACIONAL SOBRE SAÚDE MENTAL NO TRABALHO, 2., Anais..., 2006, Goiânia, CIR, p. 64-98, 2007.

. Trabalho e desgaste mental: o direito de ser dono de si mesmo. São Paulo: Cortez, 2011. 